
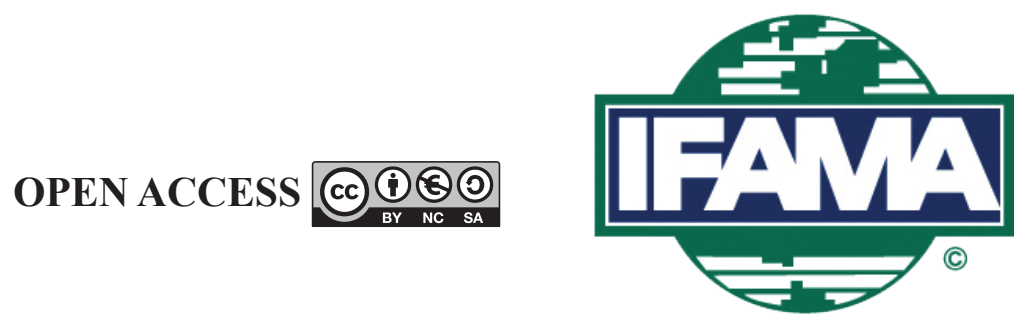

International Food and Agribusiness Management Review

Volume 23, Issue 3, 2020; DOI: 10.22434/IFAMR2019.0172

Received: 10 June 2019 / Accepted: 10 March 2020

\title{
The dynamic impact of international agricultural commodity price fluctuation on Chinese agricultural commodity prices
}

RESEARCH ARTICLE

\author{
Xiaoyu Zhang ${ }^{(\mathbb{1} a}$ and Yongfu Liu ${ }^{\mathrm{b}}$ \\ ${ }^{a}$ Professor, ${ }^{b} \mathrm{Dr}$, Center for Quantitative Economics of Jilin University, \\ 2699 Qianjin St., Changchun 130012, Jilin, China P.R.
}

\begin{abstract}
The correlation between Chinese and international commodity prices may be nonlinear because of China's minimum agricultural commodity purchase price policy and temporary storage policy. In order to research this nonlinear dynamic correlation mechanism, we construct a nonlinear Granger causality test model and a nonlinear autoregressive distribution lag model including Chinese and international agricultural commodity (soybean, corn, rice, and wheat) price variables. Our empirical results reveal that a unidirectional causal relation exists between international and Chinese prices for soybeans and corn; specifically, international prices of soybeans and corn Granger-cause Chinese prices of soybeans and corn. Moreover, the pass-through effects between Chinese and international commodity prices are asymmetric; Chinese agricultural commodity prices respond more strongly to positive shocks than negative shocks of international agricultural commodity prices.
\end{abstract}

Keywords: international agricultural commodity price, domestic agricultural commodity price, asymmetry, nonlinear Granger causality, NARDL model

JEL code: Q13, Q17

(1)Corresponding author: xiao_yu@jlu.edu.cn 


\section{Introduction}

Agricultural commodity prices have an important impact on both producers and consumers. Therefore, maintaining agricultural commodity price stability has been a concern of both government departments and academic research. To ensure agricultural commodity security, make up for agricultural commodity shortages, and stabilize the income of farmers, China has introduced a minimum agricultural commodity purchase price policy and a temporary storage policy. Because of these changes along with China's reform and opening-up policies, the correlation between the Chinese agricultural market and the international agricultural market has gradually increased. This has led to a corresponding increase in the impact of changes in international agricultural commodity prices on the Chinese agricultural market. At the same time, the Chinese agricultural market has experienced problems, such as the rise of agricultural commodity stocks, the sharp increase in imports, and an expansion of the price gap between domestic and international agricultural commodities. These new economic conditions make it necessary to accurately measure the dynamic impact of international agricultural commodity price changes on Chinese agricultural commodity prices and to explore the correlation mechanism between the international and Chinese agricultural markets.

When analyzing trade policy reform in global agricultural markets, the extent to which domestic agricultural commodity markets in developing countries respond to changes in international prices is a fundamental issue. To understand the extent of the integration of economic agents in the market process, price transmission from the world to domestic markets remains central. Studies on the transmission of price signals are founded on concepts related to competitive pricing behavior (Fackler and Goodwin, 2001). In spatial terms, the classical paradigm of the 'law of one price,' as well as the predictions on market integration provided by standard spatial price determination models (Takayama and Judge, 1973) postulate that price transmission is complete when equilibrium prices of a commodity sold on competitive foreign and domestic markets differ only in transfer costs when converted to a common currency. The implementation of import tariffs, in general, allows international price changes to be fully transmitted to domestic markets in relative terms. Thus, at all points in time, a proportional increase in the international price will result in an equal, proportional increase in the domestic price, provided that tariff levels remain unchanged. However, if the tariff level is prohibitively high, changes in the international price are only partly transmitted to the domestic market, as domestic prices may be close to the autarky price level, thus obliterating opportunities for spatial arbitrage and resulting in the two prices moving independently of each other, as if an import ban were implemented. Other policy instruments such as tariff rate quotas may result in international price changes not always being proportionately transmitted to domestic prices, as changes in the domestic price level then depend on two different tariff rates that are applied according to whether the volume of imports falls within - or outside - the quota level. The implementation of price support policies, such as intervention mechanisms and floor prices, may result in the international and the domestic price being completely unrelated or being related in a nonlinear manner, depending on the level of the intervention or floor price relative to the international price. Hence, floor price policies may result in the domestic price being completely unrelated to the international market below a certain threshold determined by the floor price, or in the two prices being related in a nonlinear manner with increases in the international price being fully transmitted to the domestic level, while decreases are slowly and incompletely passed through (Baltzer, 2013; Rapsomanikis et al, 2006).

Since China's accession to the World Trade Organization at the end of 2001, the Chinese and international agricultural commodity markets have become increasingly connected, the scale of agricultural commodity imports has expanded, and the openness of agricultural products has gradually deepened. Therefore, we explored whether the changes in international agricultural commodity prices have had a nonlinear impact on the Chinese agricultural commodity market and whether the impact of international agricultural commodity price increases and declines have had an asymmetrical impact on the Chinese market. In this study, we analyze the nonlinear correlation mechanism between the international agricultural commodity market and the Chinese agricultural commodity market by constructing a nonlinear Granger causality test model and a nonlinear autoregressive distribution lag model. Our analysis puts forth insights and reasonable policy 
suggestions with the goal of improving agricultural commodity security policies to provide a policy reference and decision-making basis to ensure that Chinese agricultural commodity prices remain stable.

The implementation of the agricultural commodity circulation system reform in China in the 1990s led to the academic study of the relationship between international agricultural commodity markets and Chinese agricultural commodity markets. Since China joined the World Trade Organization, relevant research has grown. Early on, researchers tended to use classical linear econometric models, such as cointegration analysis, the Granger causality test, and error correction models. For example, Alexander and Wyeth (1994) used the cointegration method to analyze the Indonesian rice market. The results showed that the rice market in different regions of Indonesia had a significant cointegration relationship. Silvapulle and Jayasuriya (1994) studied the rice market in the Philippines and Manila using the Johansen cointegration test. Their study found a significant cointegration relationship in the long run. Garcia and Salayo (2009) used the Granger causality test model to examine the causal relationship between different agricultural prices in the Philippines. Piggott (2001) used an error correction model to analyze the dynamic impact mechanisms of soybean and corn markets in North Carolina. Meyer (2004) investigated the European agricultural market by constructing a vector error correction model; the study found that there was a strong cointegration relationship between different markets. These results show that these markets had significant cointegration relationships.

Chinese scholars have also used the above econometric models to analyze the cointegration relationships between Chinese and international agricultural commodity markets. Wu (2001) used the Granger causality test to analyze the internal linkage mechanism of the soybean, corn, rice and wheat markets between China and the world. The results showed that both the soybean and corn markets in China and the world had a strong correlation, while the Chinese and international rice and wheat markets were weakly correlated. This was because the total trade volume of soybeans and corn was large, while the rice and wheat markets were still self-sufficient. As a result, the Chinese soybean and corn markets had a high degree of cointegration with international soybean and corn markets, while the Chinese rice and wheat markets had a low degree of correlation with international rice and wheat markets. With China's successful admission to the World Trade Organization, the government implemented a minimum purchase price policy and a temporary storage policy for agricultural products in 2004 to protect the income of domestic agricultural producers; however, China has gradually liberalized its agricultural markets in accordance with trade rule requirements, which has increased the degree of correlation between the Chinese and international rice and wheat markets. The following studies also find increasing correlations between Chinese and international commodities markets. Ding (2009), and Gao and Gong (2012) used cointegration tests and vector error correction models to investigate the price transfer relationship between Chinese and international agricultural commodities such as rice, wheat, corn and soybeans. Their research found that whether from the perspective of long-term cointegration or short-term fluctuations, the changes in international agricultural commodity prices affected China to varying degrees. Luo and Niu (2009) used a cointegration test and vector autoregression model to analyze the transfer effect of international agricultural price fluctuation on Chinese agricultural prices. Their study found that there was a cointegration relationship between Chinese and international agricultural prices; the change in international agricultural prices had a significant impact on Chinese agricultural prices.

The classical linear econometric model suggests that the positive and negative fluctuations of international agricultural commodity prices have a symmetrical effect on the Chinese agricultural commodity market. However, with the continuous improvement of econometric methods and the gradual deepening of research on the correlation mechanism between Chinese and international agricultural commodity markets, focusing on strict linear relationships for the operational mechanism of the real market has been questioned. The academic community began to study the dynamic dependence of the agricultural products market - in China and international - by constructing nonlinear econometric models. Serra and Goodwin (2003) used the threshold vector error correction model to measure the price relationship and transmission mechanism of Spanish dairy products, farms, and retail markets. Their empirical results showed that there was a nonlinear influence mechanism. Based on the perspective of international market factors, Gu and Fang (2010) used the Markov regime switching vector error correction model to measure the impact of international market 
factors on Chinese agricultural commodity prices. They concluded that the international market factors had an asymmetric effect on the price of Chinese agricultural products. Peng et al. (2016) analyzed the asymmetric response of Chinese agricultural commodity prices to international price shocks under different economic conditions using the Markov switching model with time-varying transition probabilities. They found an asymmetric effect of international agricultural commodity prices on Chinese agricultural commodity prices through trade routes. Serra et al. (2008) used the smooth transfer vector error correction model to analyze the nonlinear correlation mechanism among the prices of corn, ethanol, and gasoline in the United States. The impulse curve showed that the price changes of ethanol and gasoline had an asymmetric effect on the price of corn. Saghaian et al. (2018) used the nonlinear BEKK-multivariate-GARCH model to examine the dynamic relationship between the U.S. corn and energy markets. The empirical results demonstrate that there was an asymmetric wave transfer mechanism between corn and energy prices. Han (2018) studied the nonlinear transmission mechanism of international agricultural commodity prices to Chinese agricultural commodity prices based on a threshold autoregressive model. Their results showed that soybean and corn markets with higher openness had stronger responses to external shocks.

The above literature shows that academic research on the dynamic relation between the domestic and international agricultural commodity markets has changed from using the classical linear model to the complex nonlinear model. Academic research has also transformed its understanding of the market operation mechanism, moving from the application of strict symmetry constraints to the introduction of nonlinear assumptions. The existing literature using nonlinear econometric models has significantly improved the accuracy of identifying transmission mechanisms between markets and the effectiveness of policy simulations. Please note that the existing literature remains at the static level when measuring the asymmetrical influence effect between markets - that is, the cointegration coefficient between markets is different under different economic conditions. However, whether the dynamic adjustment mode of the market tending to a new steady state after exhibiting an external shock exhibits an asymmetrical feature has not been fully investigated. On the basis of investigating whether different agricultural commodity markets in China and the world have static asymmetry characteristics, we tested whether the short-term dynamic adjustment pattern displayed asymmetry.

There are several reasons for using the nonlinear model. First, the transmission mechanism of Chinese and international agricultural commodity prices in real economic activities is nonlinear; therefore, it makes sense to use a nonlinear Granger causality test model and the nonlinear autoregressive distribution lag model to study the correlation mechanism between Chinese and international agricultural commodity prices. Prior studies have mainly used a linear causality test model to analyze the impact of international agricultural prices on Chinese agricultural prices, so their conclusions may be contrary to the nonlinear transmission mechanism. Second, in using the nonlinear autoregressive distribution lag model, we were able to calculate the long-term asymmetric effect and short-term adjustment model of the impact of international agricultural price fluctuations on Chinese agricultural prices. This illustrates the long-term asymmetric impact of rising and falling international agricultural commodity prices on Chinese agricultural commodity prices as well as provides empirical support for policy makers to formulate reasonable economic and trade policies, thereby mitigating the adverse impact of international agricultural price fluctuations on Chinese markets.

The rest of the paper is organized as follows: the next section introduces the econometric model, including the nonlinear Granger causality test model and the nonlinear autoregressive distribution lag model. Empirical tests and an analysis of the results are provided in Section 3, followed by our conclusions in Section 4. 


\section{Methods}

\subsection{Nonlinear Granger causality test model}

We used the nonlinear Granger causality test method proposed by Péguin-Feissolle et al. (2008) to examine the impact mechanism of international agricultural commodity prices and domestic agricultural commodity prices. We let $\Delta y_{t}$ and $\Delta x_{t}$ represent the first-order logarithmic difference between domestic agricultural commodity prices and foreign agricultural commodity prices, respectively. We discovered a nonlinear functional relationship with an unknown form:

$$
\begin{aligned}
& \Delta y_{t}=f_{y}\left(\Delta y_{t-1}, \Delta y_{t-2}, \cdots, \Delta y_{t-p}, \Delta x_{t-1}, \Delta x_{t-2}, \cdots, \Delta x_{t-p} ; \phi_{y}\right)+\varepsilon_{y t} \\
& \Delta x_{t}=f_{x}\left(\Delta y_{t-1}, \Delta y_{t-2}, \cdots, \Delta y_{t-p}, \Delta x_{t-1}, \Delta x_{t-2}, \cdots, \Delta x_{t-p} ; \phi_{x}\right)+\varepsilon_{x t}
\end{aligned}
$$

The symbols $f_{x}(\bullet)$ and $f_{y}(\bullet)$ represent unknown functions; $\phi_{x}$ and $\phi_{y}$ correspond to parameter vectors in the function; $\varepsilon_{x t}$ and $\varepsilon_{y t}$ are irrelevant to each other; and $\varepsilon_{x t} \sim$ i.i.d. $N\left(0, \sigma^{2}{ }_{x}\right), \varepsilon_{y t} \sim$ i.i.d.N $\left(0, \sigma^{2}{ }_{y}\right)$.

If:

$$
f_{y}\left(\Delta y_{t-1}, \Delta y_{t-2}, \cdots, \Delta y_{t-p}, \Delta x_{t-1}, \Delta x_{t-2}, \cdots, \Delta x_{t-p} ; \phi_{y}\right)=f_{y}^{*}\left(\Delta y_{t-1}, \Delta y_{t-2}, \cdots, \Delta y_{t-p} ; \phi_{y}^{*}\right)
$$

This indicates that the lag value of $\Delta x_{t}$ is not helpful for predicting $\Delta y_{t}$, which is called $\Delta x_{t}$ not Granger-causing $\Delta y_{t}$. Similarly, the hypothesis of $\Delta y_{t}$ not Granger-causing $\Delta x_{t}$ can be tested. Since the nonlinear function relationship between $\Delta y_{t}$ and $\Delta x_{t}$ is unknown, the Granger causality of $\Delta y_{t}$ and $\Delta x_{t}$ could not be tested by the method of parameter constraints. For this reason, it was necessary to parameterize the unknown function. To better approximate a nonlinear relationship between $\Delta y_{t}$ and $\Delta x_{t}$, the second-order Taylor approximation of $f_{x}(\bullet)$ and $f_{y}(\bullet)$ at $\Delta x_{t-j}, \Delta y_{t-j}=0$ is usually used:

$$
\begin{aligned}
& \Delta y_{t}=c_{y}^{*}+\sum_{j=1}^{p} \alpha_{y j}^{*} \Delta y_{t-j}+\sum_{j=1}^{p} \beta_{y j}^{*} \Delta x_{t-j}+\sum_{j_{1}=1}^{p} \sum_{j_{2}=j_{1}}^{p} \alpha_{y j_{j} j_{2}}^{*} \Delta y_{t-j_{1}} \Delta y_{t-j_{2}}+\sum_{j_{1}=1}^{p} \sum_{j_{2}=1}^{p} \lambda_{y j_{j} j_{2}}^{*} \Delta y_{t-j_{1}} \Delta x_{t-j_{2}}+\sum_{j_{1}=1}^{p} \sum_{j_{2}=j_{1}}^{p} \beta_{y j_{1} j_{2}}^{*} \Delta x_{t-j_{1}} \Delta x_{t-j_{2}}+\varepsilon_{y t} \\
& \Delta x_{t}=c_{x}^{*}+\sum_{j=1}^{p} \alpha_{x j}^{*} \Delta x_{t-j}+\sum_{j=1}^{p} \beta_{x j}^{*} \Delta y_{t-j}+\sum_{j_{1}=1}^{p} \sum_{j_{2}=j_{1}}^{p} \alpha_{x x_{1} j_{2}}^{*} \Delta x_{t-j_{1}} \Delta x_{t-j_{2}}+\sum_{j_{1}=1}^{p} \sum_{j_{2}=1}^{p} \lambda_{x j_{1} j_{2}}^{*} \Delta x_{t-j_{1}} \Delta y_{t-j_{2}}+\sum_{j_{1}=1}^{p} \sum_{j_{2}=j_{1}}^{p} \beta_{x j_{1} j_{2}}^{*} \Delta y_{t-j_{1}} \Delta y_{t-j_{2}}+\varepsilon_{x t}
\end{aligned}
$$

The above system is a parameterized equation about $\Delta y_{t}$ and $\Delta x_{t}$, so the Granger causality test between $\Delta y_{t}$ and $\Delta x_{t}$ can be realized by the method of the parameter constraint test.

$$
\text { If: } \beta_{y j}^{*}=\lambda_{y j_{1} j_{2}}^{*}=\beta_{y j_{1} j_{2}}^{*}=0, j, j_{1}, j_{2}=1,2, \cdots, p
$$

then the variable $\Delta x_{t}$ is not Granger-causing the variable $\Delta y_{t}$. Similarly, the null hypothesis of $\Delta y_{t}$ not Grangercausing $\Delta x_{t}$ can be tested by parameter constraints.

In particular, when $p=1$, Equation 1 degenerates into the following form:

$$
\begin{aligned}
& \Delta y_{t}=f_{y}\left(\Delta y_{t-1}, \Delta x_{t-1} ; \phi_{y}^{\prime}\right)+\varepsilon_{y t} \\
& \Delta x_{t}=f_{x}\left(\Delta y_{t-1}, \Delta x_{t-1} ; \phi_{x}^{\prime}\right)+\varepsilon_{x t}
\end{aligned}
$$

If $f_{y}\left(\Delta y_{t-1}, \Delta x_{t-1} ; \phi_{y}^{\prime}\right)=f_{y}^{*}\left(\Delta y_{t-1} ; \phi_{y}^{\prime *}\right)$, this indicates that the lag value of $\Delta x_{t}$ is not helpful for predicting $\Delta y_{t}$, which is called $\Delta x_{t}$ not Granger-causing $\Delta y_{t}$. In order to better approximate the nonlinear relationship between $\Delta y_{t}$ and $\Delta x_{t}$, the second-order Taylor approximation of $f_{x}(\bullet)$ and $f_{y}(\bullet)$ at $\Delta x_{t-j}, \Delta y_{t-j}=0$ is usually used:

$$
\begin{aligned}
& \Delta y_{t}=c_{y}^{*}+\alpha_{y 1}^{*} \Delta y_{t-1}+\beta_{y 1}^{*} \Delta x_{t-1}+\alpha_{y 11}^{*} \Delta y_{t-1} \Delta y_{t-1}+\lambda_{y 1}^{*} \Delta y_{t-1} \Delta x_{t-1}+\beta_{y 11}^{*} \Delta x_{t-1} \Delta x_{t-1}+\varepsilon_{y t} \\
& \Delta x_{t}=c_{x}^{*}+\alpha_{x 1}^{*} \Delta x_{t-1}+\beta_{x 1}^{*} \Delta y_{t-1}+\alpha_{x 11}^{*} \Delta x_{t-1} \Delta x_{t-1}+\lambda_{x 11}^{*} \Delta x_{t-1} \Delta y_{t-1}+\beta_{x 11}^{*} \Delta y_{t-1} \Delta y_{t-1}+\varepsilon_{x t}
\end{aligned}
$$


Based on Equation 6, the Granger causality test between $\Delta x_{t}$ and $\Delta y_{t}$ can be realized by a parameter constraint test:

$$
\text { If } \beta_{y 1}^{*}=\lambda_{y 11}^{*}=\beta_{y 11}^{*}=0
$$

then the variable $\Delta x_{t}$ is not Granger-causing the variable $\Delta y_{t}$.

Although the nonlinear function relationship between $\Delta y_{t}$ and $\Delta x_{t}$ represented by Equation 1 can be parameterized by the second-order Taylor approximation, the estimate presents another problem: too many parameters are introduced, which reduces the test efficiency of the subsequent parameter constraint test. Therefore, to reduce the parameters, the principal components must be extracted from the corresponding variables of the constraint parameters. As the first equation and the second equation of Equation $3, k_{y}$ and $k_{x}$ principal components $F_{y}^{1}, F_{y}^{2}, \cdots, F_{y}^{k_{y}}$ and $F_{x}^{1}, F_{x}^{2}, \cdots, F_{x}^{k_{x}}$ can be extracted for the variables $\Delta x_{t-j}, \Delta y_{t-j 1} \Delta x_{t-j 2}$, $\Delta x_{t-j 1} \Delta x_{t-j 2}\left(j, j_{1}, j_{2}=1,2, \ldots, p\right)$, and $\Delta y_{t-j}, \Delta x_{t-j 1} \Delta y_{t-j 2}, \Delta y_{t-j 1} \Delta y_{t-j 2}\left(j, j_{1}, j_{2}=1,2, \ldots, p\right)$, respectively. Thus, Equation 3 can be rewritten as:

$$
\begin{aligned}
& \Delta y_{t}=c_{y}^{*}+\sum_{j=1}^{p} \alpha_{y j}^{*} \Delta y_{t-j}+\sum_{j_{1}=1}^{p} \sum_{j_{2}=j_{1}}^{p} \alpha_{y j_{1} j_{2}}^{*} \Delta y_{t-j_{1}} \Delta y_{t-j_{2}}+\sum_{j=1}^{k_{y}} \delta_{y j} F_{y}^{j}+\varepsilon_{y t} \\
& \Delta x_{t}=c_{x}^{*}+\sum_{j=1}^{p} \alpha_{x j}^{*} \Delta x_{t-j}+\sum_{j_{1}=1}^{p} \sum_{j_{2}=j_{1}}^{p} \alpha_{x j_{1} j_{2}}^{*} \Delta x_{t-j_{1}} \Delta x_{t-j_{2}}+\sum_{j=1}^{k_{x}} \delta_{x j} F_{x}^{j}+\varepsilon_{x t}
\end{aligned}
$$

At this point, the Granger causality test between the variables $\Delta x_{t}$ and $\Delta y_{t}$ can be verified by examining the null hypotheses $\left(H_{0}: \delta_{y 1}=\delta_{y 2}=\delta_{y k y}=0\right.$ and $\left.H_{0}: \delta_{x 1}=\delta_{x 2}=\delta_{x k x}=0\right)$. Based on the second-order Taylor approximation to extract the principal components to characterize the short-term interaction between $\Delta x_{t}$ and $\Delta y_{t}$, the Granger causality test can be carried out by using the single equation estimation method or the system estimation method to construct the constraining test statistics in the form of Lagrange multipliers. The Lagrange multiplier test statistics constructed by the single equation and the system estimation method are:

$$
L M_{\text {nonline-single }}=\frac{\left(R S S_{0}-R S S_{1}\right) / k_{i}}{R S S_{1} /\left(T-k_{i}-1\right)} \sim F\left(k_{i}, T-k_{i}-1\right), \quad i=y, x
$$

and

$$
L M_{\text {nonline-system }}=\frac{T}{k_{i}}\left(m-\operatorname{tr}\left(U_{1}^{\prime} U_{1}\left(U_{0}^{\prime} U_{0}\right)^{-1}\right)\right) \sim F\left(k_{i}, T\right), \quad i=y, x
$$

Where $L M_{\text {nonline-single }}$ and $L M_{\text {nonline-system }}$ represented the Lagrange multiplier test statistics of the nonlinear Granger causality test based on one equation and system estimation methods, respectively. $R S S_{1}$ and $R S S_{0}$ represent the sum of squared residuals of unconstrained regression and constrained regression in the parameter constraint test, respectively. $U_{1}$ and $U_{0}$ are the $T \times m$-dimensional residual matrices corresponding to the unconstrained and constrained regressions of the system equation, respectively. $T$ represents the number of sample observations, $m$ is the number of equations in the system and $\operatorname{tr}(\cdot)$ is the trace of the matrix. The $L M_{\text {nonline-single }}$ and $L M_{\text {nonline-system }}$ test statistics were subject to the $F$ distribution. The $L M_{\text {nonline-single }}$-test statistic was based on a single equation. Taking the first equation in Equation 1 as an example and assuming that $\Delta x_{t}$ are the Granger-cause of $\Delta y_{t}$, it can be tested by the $L M_{\text {nonline-single }}$-test statistic, but the underlying assumption is that $\Delta y_{t}$ is not the Granger-cause of $\Delta x_{t}$. When $\Delta y_{t}$ may be the Granger-cause of $\Delta x_{t}$, the $L M_{\text {nonline-single }}$-test statistic fails. At this point, an equation system such as Equation 1 should be constructed, and Granger causality between $\Delta x_{t}$ and $\Delta y_{t}$ should be tested by the $L M_{\text {nonline-system }}$-test statistic.

\subsection{The nonlinear autoregressive distributed lag model}

Before constructing the nonlinear autoregressive distribution lag model, we introduced an asymmetric cointegration regression model: 


$$
\begin{aligned}
& y_{t}=\beta^{+} x_{t}^{+}+\beta^{-} x_{t}^{-}+u_{t} \\
& \Delta x_{t}=v_{t}
\end{aligned}
$$

In the above formula, $y_{t}$ and $x_{t}$ are scalar $I(1)$ variables, and $x_{t}$ is decomposed as $x_{t}=x_{0}+x^{+}{ }_{t}+x_{t}^{-}$where $x^{+}{ }_{t}$ and $x_{t}{ }_{t}$ are partial sum processes of positive and negative changes in $x_{t}$ :

$$
x_{t}^{+}=\sum_{j=1}^{t} \Delta x_{j}^{+}=\sum_{j=1}^{t} \max \left(\Delta x_{j}, 0\right) \quad x_{t}^{-}=\sum_{j=1}^{t} \Delta x_{j}^{-}=\sum_{j=1}^{t} \min \left(\Delta x_{j}, 0\right)
$$

The above model has been widely used in empirical research. Because the explanatory variables in the model have endogeneity and serial correlation, the estimators based on ordinary least squares estimation are consistent, but the asymptotic distribution of parameter estimators is non-normal and, therefore, the hypothesis test based on normal distribution is invalid. In the existing literature on cointegration research, solutions are proposed from the perspective of static and dynamic regression. Since our study is focused on the dynamic model, we investigated the short-term and long-term asymmetrical effects between variables by extending the autoregressive distribution lag model. The specific nonlinear autoregressive distributed lag (NARDL) model is:

$$
y_{t}=\sum_{j=1}^{p} \phi_{j} y_{t-j}+\sum_{j=0}^{q}\left(\theta_{j}^{+} x_{t-j}^{+}+\theta_{j}^{-} x_{t-j}^{-}\right)+\varepsilon_{t}
$$

where $\phi_{j}$ is the autoregressive parameter, $\theta^{+}$and $\theta_{j}^{-}$are the asymmetric distributed-lag parameters, and $\varepsilon_{t}$ is an iid process with a mean of zero and constant variance, $\sigma_{\varepsilon}^{2}$. Referring to Pesaran et al. (2001), Equation 14 can be rewritten in an error correction form:

$$
\begin{aligned}
\Delta y_{t} & =\rho y_{t-1}+\theta^{+} x_{t-1}^{+}+\theta^{-} x_{t-1}^{-}+\sum_{j=1}^{p-1} \gamma_{j} \Delta y_{t-j}+\sum_{j=0}^{q-1}\left(\varphi_{j}^{+} \Delta x_{t-j}^{+}+\varphi_{j}^{-} \Delta x_{t-j}^{-}\right)+\varepsilon_{t} \\
& =\rho \xi_{t-1}+\sum_{j=1}^{p-1} \gamma_{j} \Delta y_{t-j}+\sum_{j=0}^{q-1}\left(\varphi_{j}^{+} \Delta x_{t-j}^{+}+\varphi_{j}^{-} \Delta x_{t-j}^{-}\right)+\varepsilon_{t}
\end{aligned}
$$

where $\rho=\sum_{j=1}^{p} \phi_{j}-1, \gamma_{j}=-\sum_{i=j+1}^{p} \phi_{i}, j=1, \ldots, q-1, \theta^{+}=\sum_{j=0}^{q} \theta_{j}^{+}, \theta^{-}=\sum_{j=0}^{q} \theta_{j}^{-}, \varphi_{0}^{+}=\theta_{0}^{+}, \varphi_{j}^{-}=-\sum_{i=j+1}^{q} \theta_{j}^{-}$, $j=1, \ldots, p-1, \varphi_{0}^{-}=\theta_{0}^{-}, \varphi_{j}^{-}=-\sum_{i=j+1}^{q} \theta_{j}^{-}, j=1, \ldots, q-1$ and $\xi_{t}=y_{t}-\beta^{+} x_{t}^{+}-\beta^{-} x_{t}^{-}$is the nonlinear error correction term where $\beta^{+}=-\theta^{+} / \rho$ and $\beta^{-}=-\theta^{-} / \rho$ are the associated asymmetrical long-run parameters.

To avoid serial correlation between the perturbation term and the explanatory variable sequence in Equation 15, we assumed that $\Delta x_{t}$ would obey the following data generation mechanism:

$$
\Delta x_{t}=\sum_{j=1}^{q-1} \Lambda_{j} \Delta x_{t-j}+v_{t} \quad v_{t} \sim N\left(0, \sigma_{v}^{2}\right)
$$

We expressed $\varepsilon_{t}$ conditionally in terms of $v_{t}$ :

$$
\varepsilon_{t}=w v_{t}+e_{t}=w\left(\Delta x_{t}-\sum_{j=1}^{q-1} \Lambda_{j} \Delta x_{t-j}\right)+e_{t}
$$

By substituting Equation 17 into 15 and rearranging it, we obtained the following nonlinear error correction model:

$$
\Delta y_{t}=\rho \xi_{t-1}+\sum_{j=1}^{p-1} \gamma_{j} \Delta y_{t-j}+\sum_{j=0}^{q-1}\left(\pi_{j}^{+} \Delta x_{t-j}^{+}+\pi_{j}^{-} \Delta x_{t-j}^{-}\right)+e_{t}
$$

where $\pi_{0}^{+}=\theta_{0}^{+}+w, \pi_{0}^{-}=\theta_{0}^{-}+w, \pi_{j}^{+}=\varphi^{+}{ }_{j}-w \Lambda_{j}, \pi_{j}^{-}=\varphi_{j}^{-}-w \Lambda_{j}, j=1, \ldots, q-1$. When given the appropriate lag order of Equation 18, the model can better overcome the endogenous and serial correlation problems of explanatory variables and improve the efficiency of hypothesis testing. 


\section{Long-term asymmetric effect}

Referring to the method proposed by Banerjee et al. (1998), we tested the constraints of coefficient $\rho$ in Equation 18. When $\rho=0$, Equation 18 degenerates into an equation containing only the difference term, meaning that there is no long-term equilibrium relationship between the variables $y_{t}, x^{+}{ }_{t}$, and $x_{t}^{-}$. Therefore, the test statistic subjected to the $t$ distribution can be tested under the condition of the null hypothesis, $H_{0}: \rho=$ 0 , and the alternative hypothesis, $H_{1}: \rho<0$, and the corresponding test statistic is recorded as $t_{B D M}$. Referring to the test method of Pesaran et al. (2001), we constructed a test statistic subject to the $F$ distribution. The corresponding null hypothesis was $H_{0}: \rho=\theta^{+}=\theta^{-}=0$, and the corresponding test statistic was recorded as $F_{P S S}$. The difference between the $t_{B D M^{-}}$-test statistic and the $F_{P S S^{-t e s t}}$ statistic is that the former imposes but does not test the implicit hypothesis $\theta^{+}=\theta^{-}=0$. Thus, the limiting distributional results were obtained under a joint hypothesis: $H_{0}: \rho=0$ and $\theta^{+}=\theta^{-}=0$.

The asymptotic distribution of the above test statistics under their null hypotheses is a non-standard distribution, and deriving the exact asymptotic distribution is very complicated due to the existence of the partial sums $x_{t}^{+}$ and $x_{t}^{-}$. Shin et al. (2014) used the bounds-testing method to perform hypothesis testing on the two scenarios in which the explanatory variables $x_{t}^{+}$and $x_{t}^{-}$were both $I(1)$ or $I(0)$ and obtained the corresponding critical values. Then, based on the obtained critical values, the critical values of all scenarios - whether the explanatory variables belonged to $I(1)$ or $I(0)$ or a combination of the two - were calculated by the bounds-testing method.

In addition, based on the regression results of the NARDL model, the constraints of $\theta^{+}=\theta^{-}$were imposed on the regression coefficients $x^{+}{ }_{t}$ and $x_{t}^{-}$in Equation 15. A Wald test statistic was constructed to test the longterm asymmetric effect, and the corresponding test statistic was recorded as $W_{L R}$. Similarly, a constraint of $\sum_{j=0}^{q-1} \varphi_{j}^{+}=\sum_{j=0}^{q-1} \varphi_{j}^{-}$was applied to the regression coefficients of the difference terms in Equation 12, and a Wald test statistic for testing short-term asymmetry effects was constructed and recorded as $W_{S R}$.

\section{Asymmetric dynamic multipliers}

Deriving asymmetric dynamic multipliers associated with unit changes in $x^{+}{ }_{t}$ and $x_{t}^{-}$on $y_{t}$ can be accomplished by rewriting Equation 18 as a nonlinear autoregressive distribution lag model in levels:

$$
\phi(L) y_{t}=\theta^{+}(L) x_{t}^{+}+\theta^{-}(L) x_{t}^{-}+e_{t}
$$

where $\phi(L)=1-\sum_{i=1}^{p} \phi_{i} L^{i}, \theta^{+}(L)=\sum_{i=0}^{q} \theta_{i}^{+} L^{i}, \theta^{-}(L)=\sum_{i=0}^{q} \theta_{i}^{-} L^{i}, \phi_{1}=\rho+1+\gamma_{1}$, and $\varphi_{i}=\gamma_{i}-\gamma_{i-1}, i=2, \ldots$, $p-1, \gamma_{p}=-\gamma_{p-1}$.

We pre-multiplied Equation 19 by the inverse of $\phi(L)$ and obtained:

$$
y_{t}=\lambda^{+}(L) x_{t}^{+}+\lambda^{-}(L) x_{t}^{-}+[\phi(L)]^{-1} e_{t}
$$

where $\lambda^{+}(L)\left(=\sum_{j=0}^{\infty} \lambda_{j}^{+}\right)=\phi(L)^{-1} \theta^{+}(L), \lambda^{-}(L)\left(=\sum_{j=0}^{\infty} \lambda_{j}^{-}\right)=\phi(L)^{-1} \theta^{-}(L)$.

The dynamic multipliers $\lambda^{+}$and $\lambda_{j}^{-}$can be calculated by the following recursive relationships in which $\lambda_{0}^{l}$ $=\theta_{0}^{l}, \phi_{j}=0$, for $j<1$ and $\lambda_{j}^{l}=0$ for $j<0$ :

$$
\lambda_{j}^{\ell}=\phi_{1} \lambda_{j-1}^{\ell}+\phi_{2} \lambda_{j-2}^{\ell}+\cdots+\phi_{j-1} \lambda_{1}^{\ell}+\phi_{j} \lambda_{0}^{\ell}+\theta_{j}^{\ell}, \quad \ell=+,-, \quad j=1,2, \ldots
$$

The cumulative dynamic multiplier effects of $x^{+}{ }_{t}$ and $x_{t}^{-}$on $y_{t}$ can be evaluated as follows:

$$
\begin{aligned}
& m_{h}^{+}=\sum_{j=0}^{h} \frac{\partial y_{t+j}}{\partial x_{t}^{+}}=\sum_{j=0}^{h} \lambda_{j}^{+} \\
& m_{h}^{-}=\sum_{j=0}^{h} \frac{\partial y_{t+j}}{\partial x_{t}^{-}}=\sum_{j=0}^{h} \lambda_{j}^{-}
\end{aligned}
$$

$$
h=0,1,2 \ldots
$$


By construction, $h \rightarrow \infty, m^{+} \rightarrow \beta^{+}$, and $m_{h}^{-} \rightarrow \beta^{-}$, where $\beta^{+}=-\theta^{+} / \rho$ and $\beta^{-}=-\theta^{-} / \rho$ are the asymmetric longrun coefficients. The NARDL model we developed measured the short- and long-term asymmetric effects between economic variables. Therefore, the model had two asymmetrical features. First, the model captured long-term asymmetry, and the corresponding expression was $\beta^{+} \neq \beta^{-}$. Second, the asymmetrical characteristics of the short-term adjustment mode could be visually observed - that is, the cumulative dynamic multiplier measured the dynamic adjustment process of the market from one equilibrium to another.

\section{Empirical analysis}

\subsection{Data selection and processing}

To test the nonlinear correlation mechanism between international and Chinese agricultural commodity prices, we constructed a nonlinear Granger causality test model and a NARDL model based on the soybean, corn, rice, and wheat markets. Referring to the research of Wang and Xie (2012), we chose CME2 soybean spot prices, US 2 yellow corn spot prices in the Gulf of Mexico, $5 \%$ broken rice spot prices in Bangkok, and No. 1 hard red winter wheat spot prices in the Gulf of Mexico to represent the prices of soybeans, corn, rice, and wheat, respectively, in the international market; logarithms were taken and recorded as $x_{s, t}, x_{c, t}, x_{r, t}$, and $x_{w, t}$, respectively. Chinese soybean, corn, rice, and wheat prices were expressed by their respective prices of the agricultural products at rural market fairs. To facilitate comparison with international markets, we used monthly exchange rate data for the RMB and the U.S. dollar to convert Chinese agricultural commodity prices into U.S. dollars. This was logarithmically denoted as $y_{s, t}, y_{c, t}, y_{r, t}$ and $y_{w, t}$.

Research by Trostle (2008) showed that international agricultural commodity prices have shown a significant upward trend since 2002. In addition, the Chinese and international agricultural commodities markets have relied on trade to establish a linkage mechanism, with China joining the WTO at the end of 2001. To fully capture the dynamic correlation mechanism between international and domestic agricultural commodity prices, the sample interval of the data selected was from January 2002 to December 2017. The international agricultural commodity price data came from the main International Monetary Fund (IMF) commodity price database. The Chinese agricultural commodity price data came from the China Agricultural Product Price Survey Yearbook of each year. The monthly exchange rate data of the U.S. dollar and the RMB came from the Wind Economic Database. The sample data selected for analysis is shown in Figure 1.

To avoid non-stationary time series data that can lead to a spurious regression phenomenon, we tested the stationarity of Chinese and international agricultural commodity price data based on an Augmented DickeyFuller test and a Phillips-Perron test conducted prior to empirical analysis. The test results are shown in Table 1. The results of the data stationarity test suggest that, whether using the Augmented Dickey-Fuller test or the Phillips-Perron test, the level data of agricultural commodity prices in Chinese and international composed a non-stationary time series, while the first-order difference series belonged to a stationary time series $(P<0.01)$. Thus, the level series of agricultural commodity prices belonged to an $I(1)$ process. 

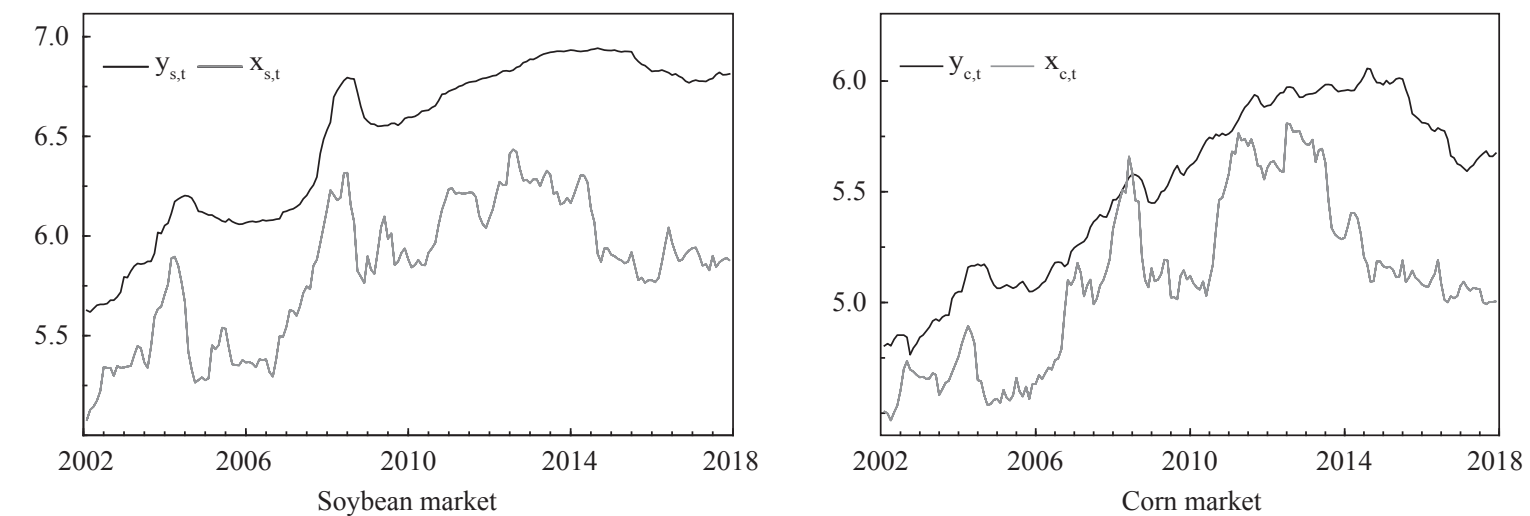

$\mathrm{C}$

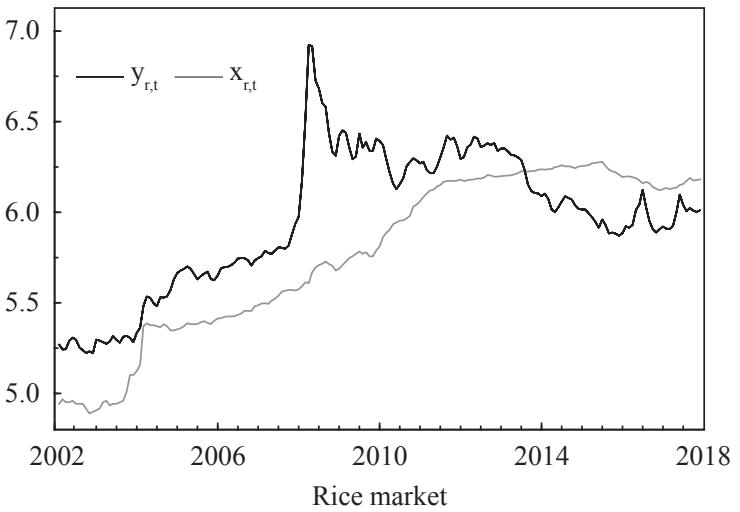

$\mathrm{D}$

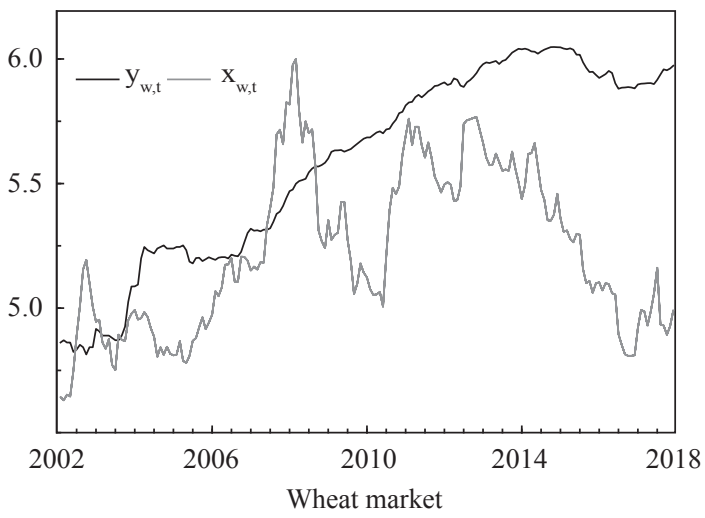

Figure 1. Agricultural commodity prices (log US\$/ton). $\left(x_{s, t}, x_{c, t}, x_{r, t}\right.$ and $x_{w, t}$, represent the prices of soybeans, corn and wheat in the international market, respectively. $y_{s, t}, y_{c, t}, y_{r, t}$ and $y_{w, t}$ represent the prices of soybeans, corn, rice and wheat on the Chinese market, respectively.)

Table 1. Data stationarity test results. ${ }^{1}$

\begin{tabular}{lcccc}
\hline Variable & \multicolumn{2}{l}{ Augmented Dickey-Fuller test } & \multicolumn{2}{l}{ Phillips-Perron test } \\
\cline { 2 - 3 } & Test value & $\boldsymbol{P}$-value & Test value & $\boldsymbol{P}$-value \\
\hline$y_{s, t}$ & -2.0563 & 0.2628 & -2.2299 & 0.1965 \\
$y_{c, t}$ & -2.0289 & 0.2743 & -1.9932 & 0.2897 \\
$y_{r, t}$ & -2.0947 & 0.2471 & -1.8752 & 0.3435 \\
$y_{w, t}$ & -2.3883 & 0.1464 & -1.8155 & 0.3722 \\
$\Delta y_{s, t}$ & $-5.0796^{* * *}$ & 0.0000 & $-7.9108^{* * *}$ & 0.0000 \\
$\Delta y_{c, t}$ & $-8.0899^{* * *}$ & 0.0000 & $-8.1103^{* * *}$ & 0.0000 \\
$\Delta y_{r, t}$ & $-10.2808^{* * *}$ & 0.0000 & $-10.1956^{* * *}$ & 0.0000 \\
$\Delta y_{w, t}$ & $-6.5495^{* * *}$ & 0.0000 & $-9.4065^{* * *}$ & 0.0000 \\
$x_{s, t}$ & -2.4963 & 0.1180 & -2.3618 & 0.1541 \\
$x_{c, t}$ & -2.0155 & 0.2801 & -1.9331 & 0.3166 \\
$x_{r, t}$ & -1.9842 & 0.2937 & -1.9705 & 0.2997 \\
$x_{w, t}$ & -2.4365 & 0.1332 & -2.3063 & 0.1711 \\
$\Delta x_{s, t}$ & $-9.4760^{* * *}$ & 0.0000 & $-9.5145^{* * *}$ & 0.0000 \\
$\Delta x_{c, t}$ & $-10.7918^{* * *}$ & 0.0000 & $-10.9359^{* * *}$ & 0.0000 \\
$\Delta x_{r, t}$ & $-8.5285^{* * *}$ & 0.0000 & $-7.2228^{* * *}$ & 0.0000 \\
$\Delta x_{w, t}$ & $-10.8653^{* * *}$ & 0.0000 & $-10.7911^{* * *}$ & 0.0000 \\
\hline 1
\end{tabular}

$1^{* * *}$ represents $P<0.01$, and the null hypothesis of the Augmented Dickey-Fuller and Phillips-Perron tests was that the sequence contained unit roots. 


\subsection{Nonlinear Granger causality test}

Since China's admission to the World Trade Organization, the Chinese agricultural commodity market has continued to be in line with the international agricultural commodity market. The degree of openness of agricultural products has deepened, and the scale of agricultural commodity imports has expanded. With the increase in the internationalization of the Chinese agricultural commodity market, the impact of international agricultural commodity price volatility on the domestic agricultural commodity market has become more and more prominent. International agricultural commodity prices rose significantly during the global agricultural commodity crisis in 2008 . Chinese agricultural commodity prices - especially for soybeans - also showed a sharp rise during the same period. However, since 2014, international agricultural commodity prices have fallen sharply, while domestic prices have been relatively stable. These differences suggest that the impact of international agricultural commodity prices on domestic agricultural commodity prices may have nonlinear characteristics. In addition, the analysis of the first section showed that the existence of tariff quota management, a minimum purchase price policy, and a temporary storage policy may have led to a nonlinear transmission mechanism between domestic and international agricultural markets ${ }^{1}$. Because of this possibility, we used the nonlinear Granger causality test method to examine the influence mechanism of international agricultural commodity prices on Chinese agricultural commodity prices. The specific Granger causality test results are shown in Table 2.

Table 2 indicates the results of the nonlinear Granger causality test between international and domestic soybean prices, international and domestic corn prices, international and domestic rice prices, and international and domestic wheat prices. The lag order of the model was automatically selected based on the SC information criterion of the linear vector autoregression model. According to the Granger causality test results in Table 2, it appears that whether based on the Lagrange multiplier test statistics constructed by the single equation or the equation system, the fluctuation of international soybean and corn prices affected the domestic soybean and corn price changes $(P<0.01$ and $P<0.10$, respectively). However, the fluctuation of domestic soybean and corn prices did not affect the international soybean and corn prices. For the rice and wheat markets, there was no significant Granger causality between international price changes and domestic price fluctuations.

The interaction between domestic and international agricultural commodity price volatility varied in different agricultural product markets. This suggests that the increase in the openness of the agricultural commodity market strengthened the correlation between the domestic market and the international market. Because China lacked the pricing power of soybeans and corn in the international market and imports of soybeans and corn in China have expanded, international soybean and corn prices had a strong impact on China's agricultural

Table 2. Nonlinear Granger causality test results. ${ }^{1}$

\begin{tabular}{lcccc}
\hline Test null hypothesis & $\boldsymbol{L M}_{\text {nonline-single }}$ & $\boldsymbol{P}$-value & $\boldsymbol{L M}_{\text {nonline-system }}$ & $\boldsymbol{P}$-value \\
\hline$\Delta x_{s, t}$ non-Granger impact $\Delta y_{s, t}$ & $17.7953^{* * *}$ & 0.0000 & $16.8089^{* * *}$ & 0.0000 \\
$\Delta y_{s, t}$ non-Granger impact $\Delta x_{s, t}$ & 0.0161 & 0.8991 & 0.0592 & 0.8080 \\
$\Delta x_{c, t}$ non-Granger impact $\Delta y_{c, t}$ & $3.1495^{*}$ & 0.0734 & $3.2822^{*}$ & 0.0674 \\
$\Delta y_{c, t}$ non-Granger impact $\Delta x_{c, t}$ & 0.8233 & 0.3772 & 0.8398 & 0.3721 \\
$\Delta x_{r, t}$ non-Granger impact $\Delta y_{r, t}$ & 0.0347 & 0.8524 & 0.0335 & 0.8550 \\
$\Delta y_{r, t}$ non-Granger impact $\Delta x_{r, t}$ & 0.6727 & 0.4281 & 0.7914 & 0.3872 \\
$\Delta x_{w, t}$ non-Granger impact $\Delta y_{w, t}$ & 1.3145 & 0.2532 & 1.3693 & 0.2435 \\
$\Delta y_{w, t}$ non-Granger impact $\Delta x_{w, t}$ & 0.9899 & 0.3299 & 1.1345 & 0.2945 \\
\hline 1
\end{tabular}

${ }^{1 *}$ and ${ }^{* * *}$ represent $P<0.10$ and $P<0.01$, respectively.

\footnotetext{
${ }^{1}$ We also attempted to identify the causal relationship between Chinese and international agricultural commodities using the linear Granger causality test. The results showed that the price change in international soybean market was the Granger-cause of the price change in the Chinese soybean market.
} 
commodity market, while the fluctuation of Chinese soybean and corn prices had no significant impact on the fluctuation of international agricultural commodity prices. In the process of agricultural commodity marketization, China has gradually increased its control over major agricultural product varieties, such as rice and wheat, thus making the interaction between Chinese and international rice and wheat prices relatively weak.

\subsection{Long-term asymmetric effect test}

The market operation mechanism does not fit perfectly with the hypothesis of the linear econometric model, and the agricultural commodities market is no exception. Many studies have shown that a significant cointegration relationship between domestic and foreign agricultural product markets exists (Ke et al., 2017; Li et al., 2015; Xiao et al., 2014), but whether the international agricultural commodity price spillover effect on domestic agricultural commodity prices has a nonlinear relationship deserves further study. The analysis in Section 1 suggests that the existence of tariff quota management, a minimum purchase price policy, and a temporary storage policy may have led to a nonlinear transmission mechanism in domestic and foreign agricultural commodities markets. Based on the nonlinear Granger causality test, this paper builds NARDL models and analyzes the dynamic dependence of each agricultural commodity market based on the soybean, corn, rice, and wheat markets ${ }^{2}$.

After determining that domestic and international agricultural commodity price data belong to the $I(1)$ series, we used NARDL models to investigate the long- and short-term nonlinear dynamic correlation mechanism between domestic and foreign agricultural commodity markets. Referring to Shin et al. (2014) regarding general to special modeling methods, we set the significance probability for the regression coefficient to 0.05 ; variables not meeting this threshold in the regression equation were gradually eliminated, and the maximum lag order of the autoregressive coefficient and the distribution lag coefficient were both set to the $12^{\text {th }}$ order.

The regression results in Table 3 indicate that the diagnostic results of constructing the NARDL model based on each agricultural commodity market rejected the long-term equilibrium coefficient as a symmetric null hypothesis. Specifically, in the soybean market, the $t_{B D M}, F_{P S S}$, and $W_{L R}$ statistics - which tested whether long-term equilibrium coefficients $L^{+}$and $L^{-}$were symmetrical - rejected the null hypothesis $(P<0.05$, $P<0.01$, and $P<0.01$, respectively). Thus, the data suggest that the long-term equilibrium coefficients of the soybean market were asymmetrical. The long-term equilibrium coefficients $L^{+}$and $L^{-}$of the soybean market were 0.6171 and 0.4508 , respectively. These values indicate that the rise and fall of international soybean prices caused domestic soybean prices to rise by $0.6171 \%$ and to fall by $0.4508 \%$, respectively. (The longterm coefficients in the model are based on a logarithm of the original data, which represented the elasticity coefficients among variables.) The impact of rising soybean prices abroad on domestic soybean prices is greater than the decline caused by falling soybean prices abroad.

In the corn market, the $t_{B D M}$ and $F_{P S S}$ statistics, which tested whether the long-term equilibrium coefficients $L^{+}$and $L^{-}$were symmetrical, rejected the null hypothesis $\left(P<0.05\right.$ and $P<0.01$, respectively). The $W_{L R}$ statistic also rejected the null hypothesis $(P<0.01)$, which indicates that the long-term equilibrium coefficients of the corn market were asymmetrical. The long-term equilibrium coefficients, $L^{+}$and $L^{-}$, in the corn market were 0.5218 and 0.3624 , respectively. The numerical values indicate that an increase of $1 \%$ in the price of corn abroad led to an increase of $0.5218 \%$ domestically, while a decrease of $1 \%$ abroad led to a decrease of $0.3624 \%$ domestically. Further, the impact of a foreign corn price rise on the domestic corn price was greater than the decline caused by its price fall. Similarly, in the rice market, the $t_{B D M}, F_{P S S}$, and $W_{L R}$ statistics rejected the hypothesis that long-term equilibrium coefficients would be symmetrical $(P<0.05, P<0.01$, and $P<0.01$. respectively), and the long-term equilibrium coefficients $L^{+}$and $L^{-}$were 0.5323 and 0.3103 , respectively. The

\footnotetext{
${ }^{2}$ We also used the linear dynamic model to examine the dynamic impact of price fluctuations in international soybean, corn, rice and wheat markets on China's corresponding agricultural commodity markets. The results show that the long-term impact coefficient of price fluctuation in the international market on the corresponding domestic markets is not significant, whether in the soybean and corn markets with greater openness or in the rice and wheat markets with less openness.
} 
numerical results show that the rise and fall of rice prices in international markets caused a rise of $0.5323 \%$ and a decrease of $0.3103 \%$ in domestic rice prices, respectively, and the impact of international rice price rise shocks on the domestic rice prices was greater than the decline caused by the price decline.

The wheat market also had significant long-term asymmetrical characteristics, and the corresponding $t_{B D M}$, $F_{P S S}$, and $W_{L R}$ statistics rejected the long-term equilibrium coefficient as a symmetric null hypothesis $(P<.05$, $P<0.01$, and $P<0.01$, respectively). However, the long-term equilibrium coefficients, $L^{+}$and $L^{-}$, in the wheat market were 0.3853 and 0.1867 , respectively, and were much smaller than the long-term equilibrium coefficients of the soybean, corn, and rice markets. The unique phenomenon of the wheat market showed that the influence of international wheat prices on domestic wheat prices was very limited, which reflects to a certain extent that China's wheat trade volume was relatively small and thus relatively isolated from the international wheat market. The soybean, corn, and rice markets with large long-term equilibrium coefficients showed a higher degree of correlation between domestic and foreign markets as well as a larger trade volume (Wang and Xie, 2012).

Based on the above analysis of each agricultural commodity market, it appears that the long-term equilibrium coefficients between different agricultural product markets at home and abroad showed asymmetrical characteristics. The long-term equilibrium coefficients from largest to smallest were the soybean market, the corn market, the rice market, and the wheat market. This shows that the integration relationship between China's soybean market and the international soybean market was the strongest, while the integration relationship between the domestic wheat market and the international wheat market was the weakest.

Table 3. NARDL model estimation results for various agricultural products markets. ${ }^{1}$

\begin{tabular}{|c|c|c|c|c|c|c|c|}
\hline \multicolumn{2}{|c|}{ Soybean market } & \multicolumn{2}{|c|}{ Corn market } & \multicolumn{2}{|c|}{ Rice market } & \multicolumn{2}{|c|}{ Wheat market } \\
\hline Var. & Coeff. & Var. & Coeff. & Var. & Coeff. & Var. & Coeff. \\
\hline$y_{s, t-1}$ & $-0.0854^{* * *}$ & $y_{c, t-1}$ & $-0.0527^{* * *}$ & $y_{r, t-1}$ & $-0.0464^{* * *}$ & $y_{w, t-1}$ & $-0.0750^{* * *}$ \\
\hline$x_{s, t-1}^{+}$ & $0.0527^{* * *}$ & $x_{c, t-1}^{+}$ & $0.0275^{* * *}$ & $x^{+}{ }_{r, t-1}$ & $0.0247^{* * *}$ & $x_{w, t-1}^{+}$ & $0.0289^{* * *}$ \\
\hline$x_{s, t-1}^{-}$ & $0.0385^{* * *}$ & $x_{c, t-1}^{-}$ & $0.0191^{* * *}$ & $x_{r, t-1}^{-}$ & $0.0144^{* *}$ & $x_{w, t-1}^{-}$ & $0.0140^{* * *}$ \\
\hline$\Delta y_{s, t-1}$ & $0.2839^{* * *}$ & $\Delta y_{c, t-1}$ & $0.3962^{* * *}$ & $\Delta y_{r, t-1}$ & $0.2156^{* * *}$ & $\Delta y_{w, t-1}$ & $0.5076^{* * *}$ \\
\hline$\Delta y_{s, t-2}$ & $0.1602^{* *}$ & $\Delta y_{c, t-5}$ & $0.1534^{* *}$ & $\Delta y_{r, t-4}$ & $0.1978^{* * *}$ & $\Delta y_{w, t-2}$ & $-0.2856^{* * *}$ \\
\hline$\Delta y_{s, t-4}$ & $0.1428^{* *}$ & $\Delta y_{c, t-10}$ & $0.1138^{*}$ & $\Delta x_{r, t-4}^{+}$ & $-0.0677^{* *}$ & $\Delta y_{w, t-3}$ & $0.1567^{* *}$ \\
\hline$\Delta y_{s, t-10}$ & $0.1250^{*}$ & $\Delta y_{c, t-12}$ & $0.2235^{* * *}$ & $\Delta x_{r, t-8}^{+}$ & $-0.0974^{* * *}$ & $\Delta y_{w, t-4}$ & $0.1337^{* *}$ \\
\hline$\Delta y_{s, t-12}$ & $-0.1369^{* *}$ & $\Delta x_{c, t-9}^{+}$ & $-0.0757^{* *}$ & $c$ & $0.2444^{* * *}$ & $\Delta y_{w, t-10}$ & $0.1967^{* * *}$ \\
\hline$\Delta x_{s, t}^{+}$ & $0.0769^{* *}$ & $\Delta x_{c, t-2}^{-}$ & $0.0905^{* * *}$ & & & $\Delta y_{w, t-12}$ & $0.1138^{* *}$ \\
\hline$\Delta x_{s, t-1}^{+}$ & $0.0871^{* *}$ & $\Delta x_{c, t-9}^{-}$ & $-0.0904^{* * *}$ & & & $\Delta x_{w, t-12}^{-}$ & $-0.0793^{* * *}$ \\
\hline$\Delta x_{s, t-5}^{-}$ & $-0.0643^{* *}$ & $c$ & $0.2610^{* * *}$ & & & $c$ & $0.3664^{* * *}$ \\
\hline$c$ & $0.4856^{* * *}$ & & & & & & \\
\hline$L^{+}$ & $0.6171^{* *}$ & $L^{+}$ & $0.5218^{* *}$ & $L^{+}$ & $0.5323^{* *}$ & $L^{+}$ & $0.3853^{* *}$ \\
\hline$L^{-}$ & $0.4508^{* *}$ & $L^{-}$ & $0.3624^{* *}$ & $L^{-}$ & $0.3103^{* *}$ & $L^{-}$ & $0.1867^{* *}$ \\
\hline $\bar{R}^{2}$ & 0.5291 & $\bar{R}^{2}$ & 0.4681 & $\bar{R}^{2}$ & 0.1867 & $\bar{R}^{2}$ & 0.4617 \\
\hline$t_{B D M}$ & $-4.9831^{* *}$ & $t_{B D M}$ & $-4.2029^{* *}$ & $t_{B D M}$ & $-3.4328^{* *}$ & $t_{B D M}$ & $-5.4229^{* *}$ \\
\hline$F_{P S S}$ & $8.6303^{* * *}$ & $F_{P S S}$ & $6.6790^{* * *}$ & $F_{P S S}$ & $6.3446^{* * *}$ & $F_{P S S}$ & $10.8185^{* * *}$ \\
\hline$W_{L R}$ & $67.2086^{* * *}$ & $W_{L R}$ & $27.7704^{* * *}$ & $W_{L R}$ & $19.0561^{* * *}$ & $W_{L R}$ & $312.7154^{* * *}$ \\
\hline$W_{S R}$ & $17.6154^{* * *}$ & $W_{S R}$ & 1.3380 & $W_{S R}$ & $2.7760^{*}$ & $W_{S R}$ & $11.4108^{* * *}$ \\
\hline
\end{tabular}


As the basis of the Consumer Price Index, based on the long-term equilibrium relationship between domestic and foreign markets, Chinese government departments need to pay more attention to the fluctuation of the international prices for soybeans, corn, and rice when regulating domestic agricultural commodity prices.

All four agricultural commodity markets showed that the impact of foreign agricultural commodity price rise shocks was greater than that of price drop shocks. The significant asymmetrical characteristics were related to China's minimum purchase price policy and temporary storage policy. In 2004, China implemented the minimum agricultural commodity purchase and storage price policies to stimulate farmers' enthusiasm for growing agricultural commodities. While protecting the income of farmers, these policies also achieved the goal of stable agricultural commodity production and guaranteed supply. At the same time, they also weakened the impact of international agricultural commodity price declines on domestic agricultural commodity prices - that is, when international agricultural commodity prices rose, it was easier to drive domestic agricultural commodity prices to keep pace with international market prices; when international agricultural commodity prices fell, domestic market policy protection had a greater impact, and thus domestic agricultural commodity prices were less affected by the decline in international agricultural commodity prices. However, since 2011, the domestic and foreign agricultural commodity supply has been oversupplied, and domestic prices have been higher than international market prices. Continuously raising the storage price is conducive to ensuring farmers' income and stimulating agricultural commodity production, but also causes problems such as high inventories and surges in imports. Under the dual goals of guaranteeing supply and income, the key to breaking the high inventory problem appears to be to correct the excessive intervention of price support policies on agricultural commodity prices, eliminate the market distortion mechanism, and establish an agricultural commodity price formation mechanism based on market pricing.

\subsection{Analysis of short-term asymmetric adjustment pattern}

In addition to testing whether the long-term equilibrium coefficient of the domestic and international agricultural commodity markets is asymmetric, the NARDL model can characterize the dynamic adjustment path of each agricultural commodity market after deviating from the steady state based on the short-term dynamic cumulative multiplier. To clearly depict the short-term dynamic adjustment path of each agricultural commodity market after deviating from the steady state, we presented a short-term nonlinear adjustment pattern of the soybean, corn, rice, and wheat markets. The NARDL model can set different models for the short-term adjustment model of the market, such as applying long-term and short-term asymmetric constraints or ensuring long-term symmetry and short-term asymmetry to the model.

Based on the regression results of the various agricultural commodity markets except for the corn market in Table 3, the $W_{S R}$ test statistic of other agricultural commodity markets rejects the null hypothesis that the short-term coefficient is symmetrical. In order to clearly depict the short-term dynamic adjustment mode of each agricultural commodity market, we applied long- and short-term asymmetrical constraints to the model and plotted a corresponding short-term dynamic adjustment path map. In addition, to compare the difference of the adjustment modes of the corresponding domestic agricultural commodity market caused by the rising and falling shocks of international agricultural commodity prices, we took the accumulated dynamic adjustment multiplier caused by the falling shocks of international agricultural commodity prices as negative and plotted the same figure together with the accumulated dynamic adjustment multiplier caused by the rising shocks of foreign agricultural commodity prices, as shown in the following figures.

Figure 2 illustrates the accumulative short-term dynamic adjustment multiplier after the soybean market deviates from the steady state. The solid line in Figure 2 represents the adjustment path for domestic soybean prices reaching the new steady state caused by the rising impact of foreign soybean prices. The dotted line represents the adjustment path for the domestic soybean price reaching the new steady state caused by the falling impact of foreign soybean prices. The short, dashed line represents the difference between the two and the corresponding standard deviation band. Based on the dynamic adjustment cumulative multiplier as plotted in Figure 2, it appears that the domestic soybean market had a significant asymmetrical short-term 


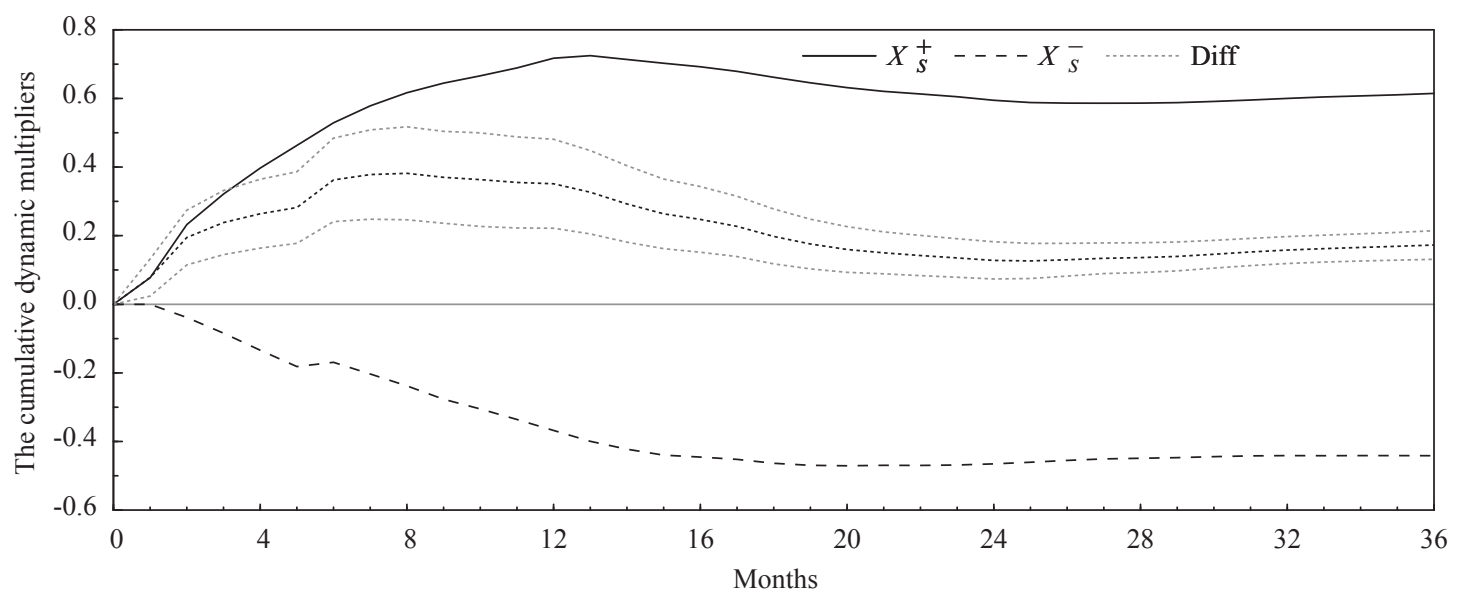

Figure 2. Long-term and short-term asymmetry in soybean market dynamic adjustment path. $X^{+}{ }_{s}$ and $X^{-}{ }_{s}$ represent the rising and falling impact of foreign soybean prices, respectively. Diff represents the difference between the both.

adjustment mode. After the domestic soybean market was shocked by foreign markets, it quickly adjusted within four months (reaching about half of the steady state values of 0.6171 and 0.4508 , but the response time for the international soybean price increase shock was shorter) and tended close to a new steady state value in 12 months. The adjustment model shows that there was a strong integration relationship between the Chinese and international soybean market. When the domestic soybean market was affected by foreign shocks, it adjusted rapidly to a new equilibrium value in about a year; the soybean market adjusted rapidly to a new equilibrium value because of its high correlation with the international market. For the trade of corn, rice, and wheat, the Chinese government has implemented state-owned proportion restrictions and import tariff quota management. For example, the import tariff quota of agricultural commodities in 2017 was 9.636 million tons of wheat ( $90 \%$ of the state-owned trade); 7.2 million tons of corn $(60 \%$ of the stateowned trade); and 5.32 million tons of rice (50\% of state-owned trade). However, for the import trade of soybeans, the Chinese government has not implemented restrictions on the state-owned proportion or the management of import tariff quotas.

Figure 3 shows the short-term dynamic adjustment cumulative multiplier after the corn market deviated from its steady state. As shown, the corn market did not demonstrate significant asymmetry in a short period of time, but it gradually showed asymmetric characteristics after about 24 months. Compared with the soybean market, the corn market tended toward the new steady state value slowly, and the short-term adjustment mode was more complex. After the domestic corn market was affected by a rise within the international market, it did not reach the new steady state value in a short time. (It reached about half of the new steady state value in seven months, but it took about 20 months to reach the new steady state value completely.)

Unlike the soybean market, the domestic corn market took longer to adjust to a new steady-state after being shocked by rising international corn prices. This longer adjustment duration indicates that there was a complex linkage mechanism in the domestic and foreign corn markets. The main uses of corn in China are feed and industrial processing. In terms of consumption structure, the total amount of edible and forage corn in China is relatively stable, while the total amount of industrial corn has risen sharply. When the price of international corn rises, the impact can be mitigated by importing sorghum, vinasse, and cassava, which are substitutes for corn. The response time of the domestic market to the impact of a rise in international corn prices is longer - that is, it is difficult for the domestic corn market to reach a new equilibrium in a short time. Therefore, the policy departments should establish a robust early warning mechanism for international corn price fluctuations, which can provide a strong guarantee for smoothing the adverse impact of external corn price fluctuations on the domestic market. 


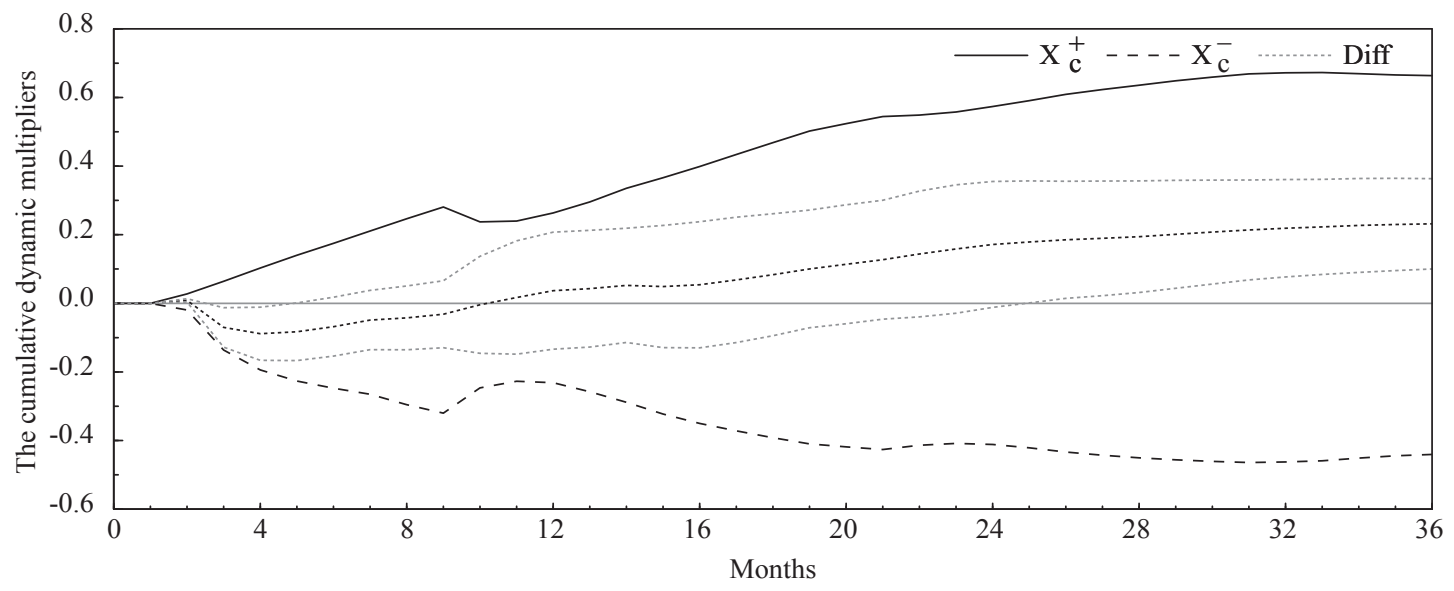

Figure 3. Long-term and short-term asymmetry in corn market dynamic adjustment paths. $X^{+}{ }_{c}$ and $X_{c}^{-}$ represent the rising and falling impact of foreign corn prices, respectively. Diff represents the difference between the both.

Figure 4 illustrates the short-term dynamic adjustment cumulative multiplier after the rice market deviated from the steady state. The illustration shows that the domestic rice market had a strong response to external positive shocks, but it took about 20 months to reach half of the new steady state value; on the other hand, the response time to external negative shocks was relatively short, and it took only about 10 months to reach half of the new steady state value. These differing responses may be related to the large stock of rice in China. The output of rice in China was 207 million tons in 2016, the sixth consecutive year in which the output exceeded 200 million tons. In addition, China's rice imports also increased year by year, and there appears to be a strange phenomenon whereby there were year-by-year increases in both the volume of domestic rice production and imports. When the international prices of rice have risen, domestic stocks of rice have buffered the market and prolonged the time required for the market to reach a new steady state. Compared to soybeans and corn, the trade volume of rice has been small, and fluctuations in the international price of rice have had little effect on domestic rice prices. However, rice is the largest agricultural crop in China, and its price changes can have a significant impact. Therefore, governmental policy departments still need to pay full attention to international rice price fluctuations.

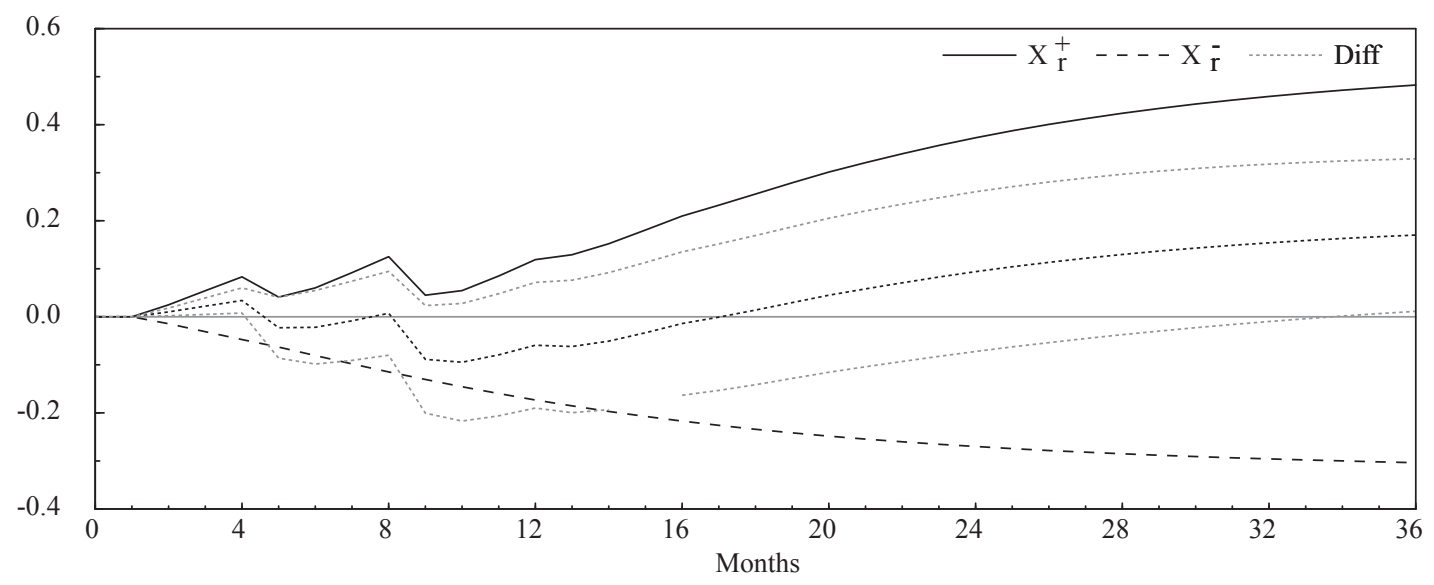

Figure 4. Long-term and short-term asymmetry rice market dynamic adjustment path. $X_{r}^{+}$and $X_{r}^{-}$represent the rising and falling impact of foreign rice prices, respectively. Diff represents the difference between the both. 
Figure 5 shows the accumulative multiplier of short-term dynamic adjustment after the wheat market deviated from the steady state. The wheat market appears to take about eight months to adjust to half of the new steady state after external shocks, but the response time for the impact of a decline in international wheat prices is relatively short. This asymmetrical feature may be related to the continued increase in the minimum purchase price of wheat. Since the implementation of the minimum purchase price policy for wheat in 2006, the market price remained high until the policy price level in 2018 ushered in the first downward adjustment. Due to the impact of the domestic minimum purchase price policy, when the domestic market was hit by a decline in international wheat prices, the adjustment to a new steady state tended to be shorter. Similar to other agricultural commodities, the wheat market showed significant asymmetry when the international market abruptly changed, but it was the least reactive of the four agricultural commodities. Rice and wheat have been less responsive to international market shocks, probably because they are consumed much more than soybeans and corn and are protected by many Chinese government policies to ensure national food security. Because of the influence of the minimum purchase price policy, the international wheat and rice price fluctuations have had relatively little impact on domestic wheat and rice prices.

As illustrated by Figures 2-5, significant differences in the impact of different international agricultural commodity prices fluctuations on domestic agricultural commodity prices exist. The reason may be that China has different market regulation levels for different agricultural commodity varieties. In the process of agricultural commodity marketization, China has gradually increased the regulation of major agricultural commodities, such as rice and wheat, and governments at various levels have implemented different policies to promote domestic agricultural commodities. These actions have enabled the government to strongly regulate and control the rice and wheat markets and have greatly stabilized the domestic agricultural commodity prices, resulting in a relatively weak interaction between domestic and international rice and wheat prices. However, for soybeans and corn, China lacks pricing power on the international market. However, since China's imports are expanding, the impact of fluctuations in the international prices of soybeans and corn on the domestic market has been relatively strong.

\section{Conclusions}

We investigated the long- and short-term nonlinear dynamic correlation mechanism between the Chinese and international soybean, corn, rice, and wheat markets by constructing a nonlinear Granger causality test model and a NARDL model. These models measured the short-term dynamic impact of fluctuations in international agricultural commodity prices on the corresponding Chinese markets. Our research showed

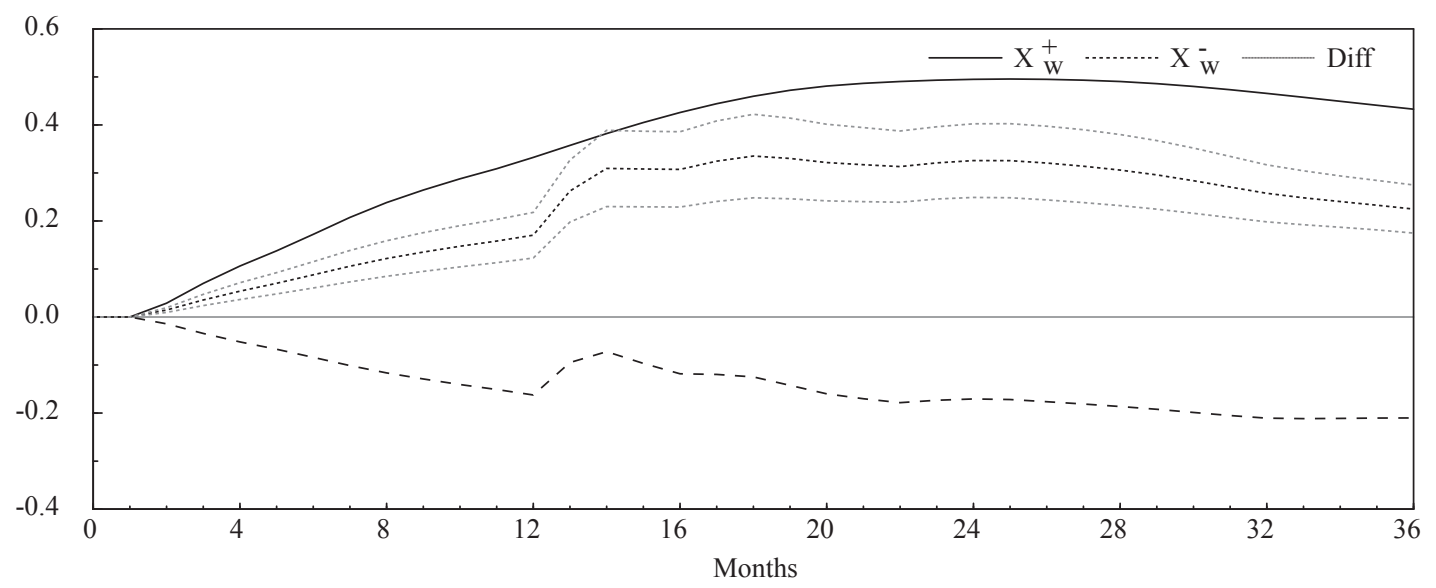

Figure 5. Long-term and short-term asymmetry in wheat market dynamic adjustment path. $X^{+}{ }_{w}$ and $X^{-}{ }_{w}$ represent the rising and falling impact of foreign wheat prices, respectively. Diff represents the difference between the both. 
that with the increasing openness of China's agricultural commodity markets and the gradual expansion of the scale of agricultural commodity imports, the fluctuation of international soybean and corn prices was the Granger-cause of the fluctuation of domestic soybean and corn prices. At the same time, because China lacks pricing power in the international markets for soybeans and corn, the fluctuation in domestic prices for soybeans and corn was not the Granger-cause of prices changes for these products on the international market. To safeguard the income of domestic agricultural producers, China has implemented tariff quota management on rice and wheat, resulting in a weak correlation between domestic and international markets and no Granger causality. In addition, China's minimum purchase price policy and temporary storage policy for agricultural commodities have led to the impact of rising international agricultural commodity prices on the domestic market, which has been greater than the impact of falling international agricultural commodity prices. This has further pushed Chinese agricultural prices far higher than international prices.

As a result of these findings, we offer the following policy recommendations: (1) While there are a variety of differences in the impact of international agricultural commodity prices on Chinese agricultural commodity prices, the domestic soybean and corn prices are highly dependent on external factors, with other agricultural commodities relatively less affected by international agricultural commodity prices. When establishing an early warning mechanism for international agricultural commodity price fluctuations in China, soybean and corn prices should be taken as core monitoring indicators. (2) Although China's minimum purchase price policy and temporary storage policy have stimulated the enthusiasm of domestic producers and guaranteed the income of farmers, problems with high agricultural commodity stocks and a sharp increase in total imports exist. To achieve the dual objectives of ensuring supply and income, China should correct the excessive intervention of price support policy in agricultural commodity prices and accelerate the establishment of a market-based agricultural commodity price formation mechanism.

\section{Acknowledgements}

This research was supported by the National Social Science Foundation of China (Grant No. 19BJY016).

\section{References}

Alexander, C. and J. Wyeth. 1994. Cointegration and market integration: an application to the Indonesian rice market. Journal of Development Studies 30(2): 303-334.

Baltzer, K.T. 2013. International to domestic price transmission in fourteen developing countries during the 2007-08 food crisis. In: P. Pinstrup-Andersen (ed.) Food price policy in an era of market instability: a political economy analysis. Oxford University Press, Oxford, UK, pp. 21-50.

Banerjee, A., B. Dolado and B. Mestre. 1998. Error-correction mechanism tests for cointegration in a singleequation framework. Journal of Time Series Analysis 19(3): 267-283.

Ding, S.H. 2009. The impact of international food price fluctuation on China's food price. Economic Science 2: 60-71.

Fackler, P.L. and B.K. Goodwin. 2001. Spatial price analysis. In: B. Gardner and G. Rausser (eds.) Handbook of Agricultural Economics. Elsevier, New York, NY, USA, pp. 971-1024.

Gao, F. and F. Gong. 2012. How international food prices affect grain prices of China? Finance and Trade Economics 11: 119-126.

Garcia, Y.T. and N.D. Salayo. 2009. Price dynamics and cointegration in the major markets of aquaculture species in the Philippines. Asian Journal of Agriculture and Development 6(1): 49-81.

Gu, G.D. and C.L. Fang. 2010. Analysis on the characteristics of agricultural product price volatility in China - based on the situation transfer model under the influence of international market factors. Chinese Rural Economy 6: 67-76.

Han, L. 2018. Asymmetric transmission of world grain price to domestic market in China - a study based on threshold autoregression model. Modern Economic Science 40(2): 78-84.

Ke, S.G., X.H. Lu, K. Ge and H.F. Li. 2017. Analysis of linkage effect between domestic and international grain prices based on overseas cultivated land investment. Chinese Rural Economy 12: 65-80. 
Li, G.W., B.M. Cao and X.L. Ma. 2015. China's grain market opening and international food price fluctuation - an analysis based on the spillover effect of grain price fluctuation. Chinese Rural Economy 8: 44-52.

Luo, F. and B.J. Niu. 2009. The pass-through effect of fluctuation of international agricultural products on domestic agricultural products: an empirical study based on VAR model. Journal of International Trade 6: 16-22.

Meyer, J. 2004. Measuring market integration in the presence of transaction costs - a threshold vector error correction approach. Agricultural Economics 31(2-3): 327-334.

Péguin-Feissolle, A., B. Strikholm and T. Teräsvirta. 2008. Testing the Granger noncausality hypothesis in stationary nonlinear models of unknown functional form. Communications in Statistics - Simulation and Computation 42(5): 1063-1087.

Peng, J.Y., R. Xie and M.Y. Lai. 2016. A study on the asymmetric impacts of international grain prices on domestic grain prices in China. Resources Science 38(5): 847-857.

Pesaran, M.H., Y. Shin and R.J. Smith. 2001. Bounds testing approaches to the analysis of level relationships. Journal of Applied Econometrics 16(3): 289-326.

Piggott, G.N.E. 2001. Spatial market integration in the presence of threshold effects. American Journal of Agricultural Economics 83(2): 302-317.

Rapsomanikis, G., D. Hallam and P. Conforti. 2006. Market integration and price transmission in selected food and cash crop markets of developing countries: review and applications. In: A. Sarris and D. Hallam (eds.) Agricultural commodity markets and trade: new approaches to analyzing market structure and instability. Food and Agriculture Organization, Rome, Italy, pp. 187-217.

Saghaian, S.H., M. Nemati and C.G. Walters. 2018. Asymmetric price volatility interaction between U.S. food and energy markets. Journal of Agricultural and Resource Economics 43: 46-60.

Serra, T. and B.K. Goodwin. 2003. Price transmission and asymmetric adjustment in the Spanish dairy sector. Applied Economics 35(18): 1889-1899.

Serra, T., D. Zilberman and J.M. Gil. 2008. Nonlinearities in the U.S. corn-ethanol-oil price system. Agricultural Economics 42(1): 35-45.

Shin, Y., B. Yu and M. Greenwood-Nimmo. 2014. Modelling asymmetric cointegration and dynamic multipliers in a nonlinear ARDL Framework. In: R. Sickles and W. Horrace (eds.) Festschrift in honor of Peter Schmidt. Springer, New York, NY, USA, pp. 281-314.

Silvapulle, P. and S. Jayasuriya. 1994. Testing for Philippines rice market integration: a multiple cointegration approach. Journal of Agricultural Economics 45(3): 369-380.

Takayama, T. and G. Judge. 1973. Spatial and temporal price and allocation models. Journal of International Economics 3(3): 304-304.

Trostle, R. 2008. Global agricultural supply and demand: factors contributing to the recent increase in food commodity prices. USDA Report, USDA, Washington, DC, USA.

Wang, X.S. and S.X. Xie. 2012. How do prices of foreign products affect prices of Chinese agricultural products? Economic Research Journal 47(3): 141-153.

Wu, L.P. 2001. Research on the relationship between domestic and foreign grain markets. China Rural Survey 1: 24-32.

Xiao, Y., C.G. Li and J. Li. 2014. Analysis of spillover effects of international grain prices on China's grain prices. Chinese Rural Economy 2: 42-55. 
